\title{
An Information-Systems Approach to Identifying Flood Risks in Central Japan
}

\author{
P. Limlahapun and H. Fukui
}

\begin{abstract}
This study explored using database environments to develop a tailor-made geospatial web-based system to identify flood risk. This approach can directly target specific needs and has advantages over existing noncommercial systems. We analyzed the river network in the Chubu region, which encompasses nine prefectures in Central Japan, to understand rainfall-water-level relationships. A spatial web-based system was then developed to monitor rainfall and river-water levels in the study area. This database system assesses near-real-time rainfall and water-level data. A map service was configured using OpenLayers, an open-source software package. This proposed system will deliver early-warning flood messages via a scripting mailer system. However, device error could occur, which necessitates human verification before a final decision is made. Self-geolocation helps individual users determine their risk. Improvements in the visualization and recognition of existing data using map-service tools and technology may help reduce tragedies and damage resulting from flooding.
\end{abstract}

Index Terms-Database information systems, map services, web-based systems, warning systems, environmental disaster, floods.

\section{BACKGROUND}

Respect for privacy and national security [1], and access to information are fundamental aspects of equality and human rights [2] regarding people's safety and security. Japan is a country that provides data to its citizens. Specially, information about disasters and related issues are available through various means (e.g., news outlets and the Internet).

Information published by government agencies covers areas at the local level and is useful in terms of detail and consistency. The Japan Meteorological Agency (JMA) provides meteorological and disaster information. The JMA announced on its website that it would launch an emergency warning system (e.g., for heavy rains, volcanic activity, tsunamis) on August 30, 2013 [3]. The Water Information System within Japan's Ministry of Land, Infrastructure and Transport provides water-related data (rainfall and rivers). Data are available from the Internet; however, there is a lack of interactive maps, and image forms can be further developed.

\section{LITERATURE REVIEW}

Database systems have grown in their application to various environmental and disaster contexts. They can be

Manuscript received August 5, 2013; revised December 4, 2013.

The authors are with the International Digital Earth Applied Science Research Center, Kasugai, Aichi, Japan (e-mail: thip.limlahapun@gmail.com, fukui@isc.chubu.ac.jp). found in many research studies (e.g., observation [4]; disaster decision support [5]-[8]; and risk management [9]-[10]. Flexible configurations for inputting large amounts of data through producing information outcome formats can aid in providing a variety of search queries and in saving time. Insufficient supporting information can lead to hazard susceptibility [6]. Investigation techniques have been explored and applied (e.g., object-oriented databases [11], object-relational GIS databases [12], and web-based databases [13]-[15]). Several studies have applied database systems to disasters; however, difficulties are likely to arise with respect to finding appropriate data (e.g., river capacity) and methods to apply rainfall and water-level data for regular monitoring, flood risk assessment and early warning system.

\section{PROBLEM STATEMENT}

Huge floods occur around the world. Bangladesh, India, and Thailand are examples of regions where people suffer as a result of heavy flooding. Research on flooding has covered various perspectives, such as monitoring, warning and forecasting. Regarding technological evolution, data disseminates rapidly, especially for disaster issues involving Japan, not just online, but also through television, mobile messages, and other media. Yet, the existing systems are inadequate (e.g., non-interactive map and near-real time alert system). Requirements have no limits; when no practices are available for particular challenges, there is a need to develop a suitable system.

This study attempted to develop a regular monitoring system for rainfall and water levels in Central Japan. This approach used existing data, technologies, and software packages to implement a functional but simple automation platform.

\section{FRAMEWORK OF THE STUDY}

An effective database distribution information system ensures that locals can receive indispensable information. This increases preparedness for flood disasters, helping to defend communities against damaging consequences.

\section{A. Study Area}

The study area comprises nine prefectures in Central Japan, covering approximately $68,250 \mathrm{~km}^{2}$ : Aichi, Nagano, Gifu, Fukui, Toyama, Niigata, Yamanashi, Ishikawa, and Shizuoka (Fig. 1). JMA data for 1981-2012 shows an average temperature of approximately $15^{\circ} \mathrm{C}$ and annual rainfall of $1,535 \mathrm{~mm}$. [3]. The central part of the study area is a mountainous range known as the Japanese Alps. The 
Northern Alps stretch through Nagano, Toyama, and Gifu; the Central Alps lie in Nagano; and the Southern Alps stretch from Yamanashi through Shizuoka (Fig. 2). The central part of the region is mountainous while urbanized areas are situated along the coastline (Fig. 3).

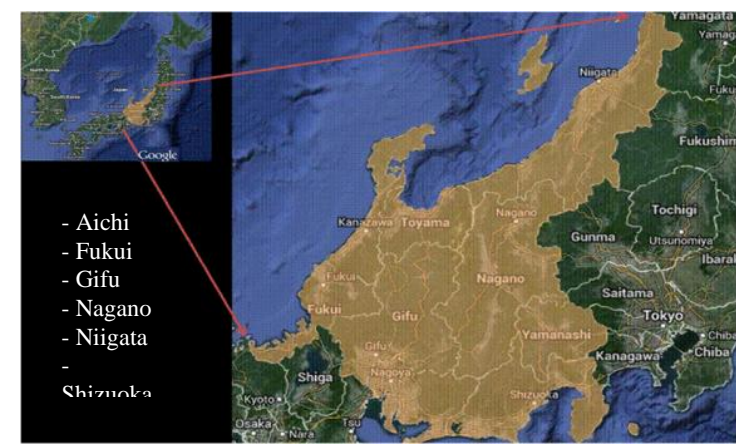

Fig. 1. Study area.

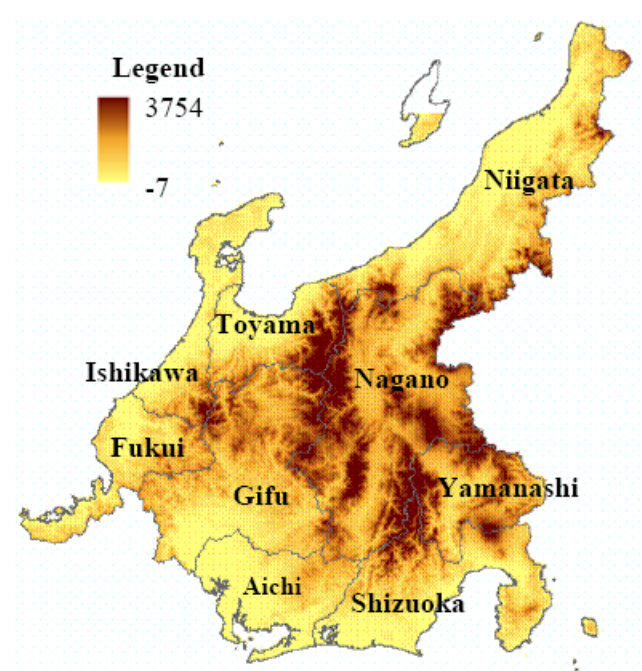

Fig. 2. Digital elevation model (DEM).

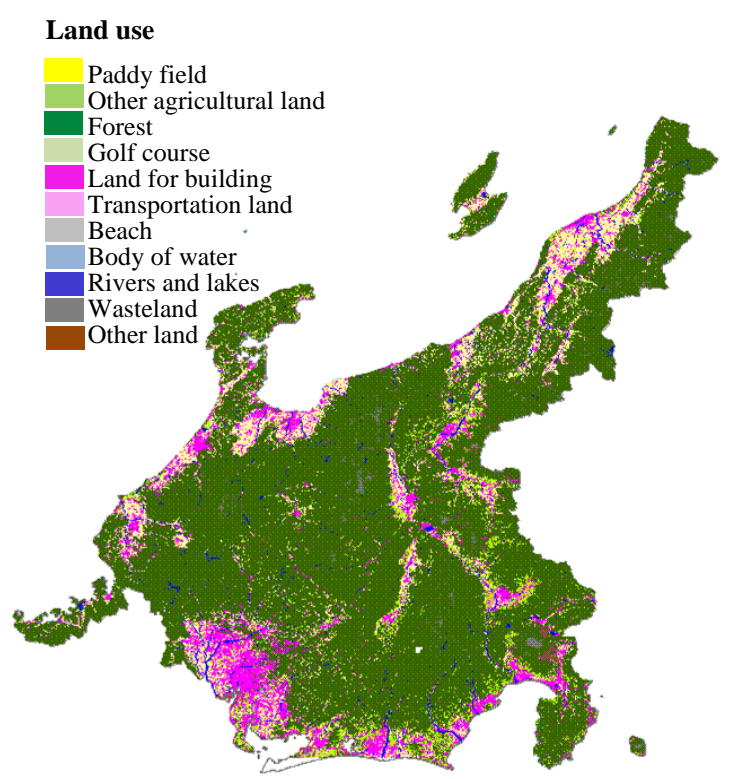

Fig. 3. Land use.

\section{B. System Overview}

The script is written to communicate within the database. The main two factors (rainfall and water-level stations) are collected for their locations and attributes. Google Maps and OpenLayers are used for the map background system. The end product includes a well-visualized map, a chart, a self-identifying function, and a warning alert. Fig. 4 shows the overall system.

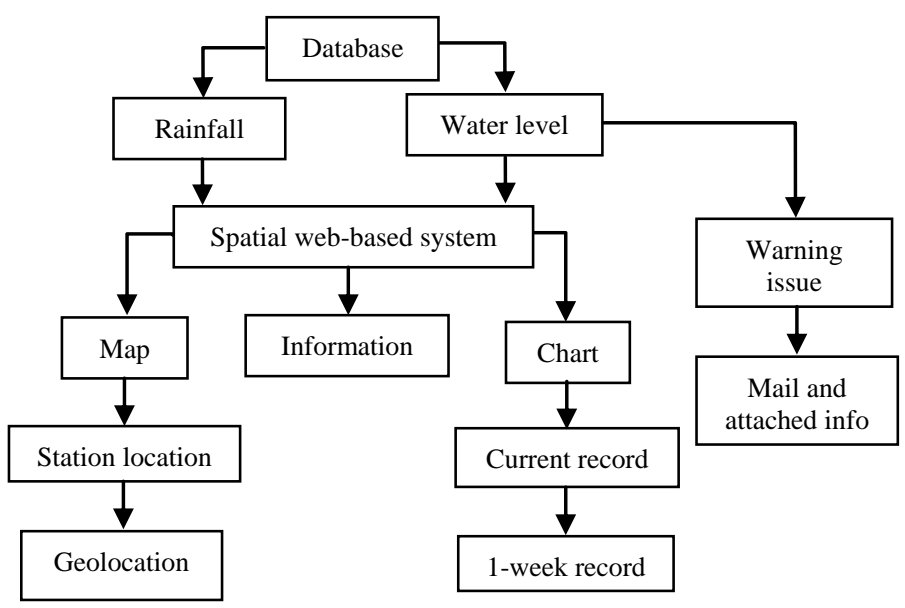

Fig. 4. The overall system.

\section{Objectives}

This paper aims to 1) understand the river network and focus on the risk areas, 2) develop a water-related spatial web-based system, 3) integrate a flood-warning message mailer system, and 4) configure self-geolocation to identify threats to individual users.

\section{METHODS}

The methods used in this study are described below.

\section{A. The Relationship between Water Level and Rainfall along the River}
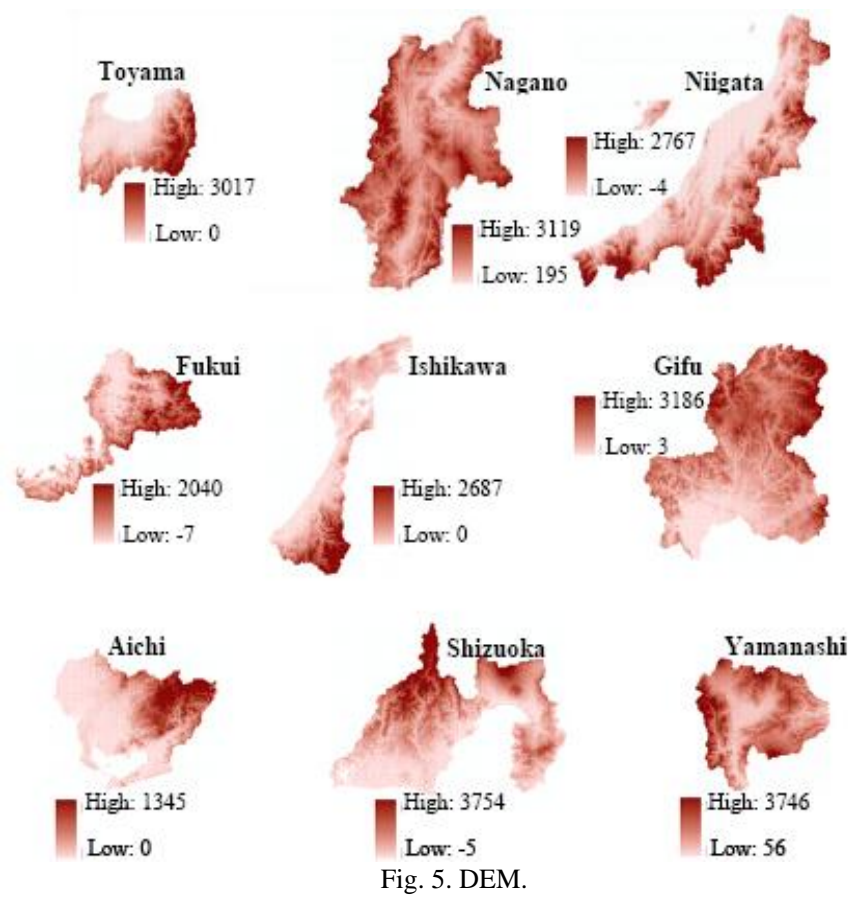

To identify the focus areas where seasonal flooding may occur, the average monthly water-level and rainfall records for 2002-2012 were collected and the relationships between the two factors were analyzed. A DEM was created using the Advanced Spaceborne Thermal Emission and Reflection 
Radiometer (Aster) Global Elevation Model (GDEM) [16] to investigate flow direction (Fig. 5). Flood risks were investigated using supporting rainfall radar images, which is provided by the JMA [3].

\section{B. Rainfall Data Retrieval and Distribution}

The necessary information for each location was collected from 389 stations (station name, latitude, longitude, and station ID). Databases and tables were constructed during the initial preparation process. There are, however, 390 tables in which each table reserves for one rainfall station (389 stations) where the extra table was used to summarize the current records (date, time, and rainfall) from each station. Those summarized values will be shown as the results in the symbol maps and tables. Data from each location are available in graph format for a one-week period. The updated rainfall records are received from the provider source (http://www1.river1.go.jp) and kept in the database for ten-minute intervals. Fig. 6 shows the process of retrieving rainfall data and the information distribution.

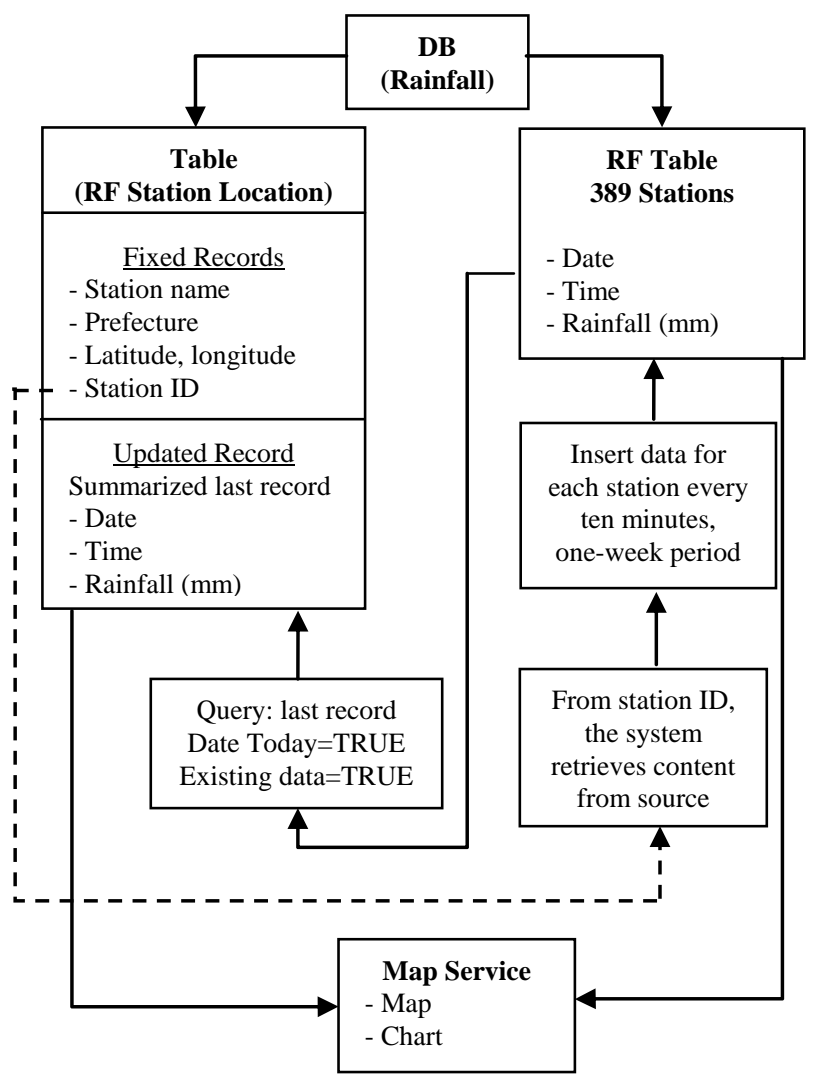

Fig. 6. Rainfall data processing system.

\section{Water-Level Data Retrieval and Distribution}

The retrieval process for water-level data is similar to the process for rainfall. However, the key for water-level implementation is used to activate the near-real time (ten-minute interval) flood warning. Due to each location along the river having the capability to retain water at difference levels, the three warning levels (warning, evacuation, and flood risk) were set for each location (238 stations in the nine prefectures). These values are suggested by the Water Information System Agency. The information available through the Internet includes the location for each station and its attributes. Users can benefit from the graph, which is drawn for one-week data records and warning-set levels. Fig. 7 shows the process of retrieving water-level data and the information distribution.

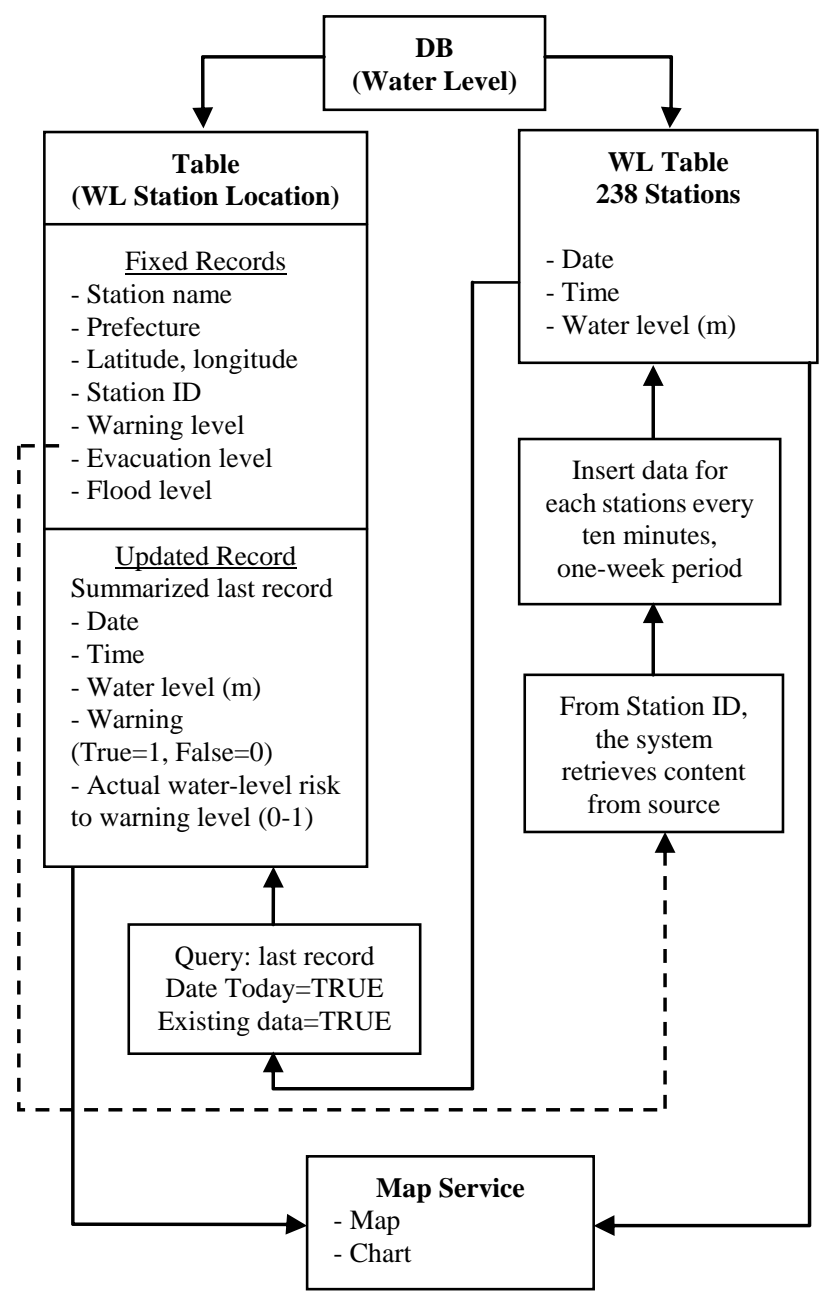

Fig. 7. Water-level data processing system.

\section{Near-Real-Time Flood Warning}

The water level is collected in ten-minute intervals to compare to the warning level. A warning value of True or False will be generated depending on whether the current water level exceeds the warning threshold value (True means the water level is higher than the threshold value; False means it is lower). When a station finds that water level exceeds river capacity, the system will generate a tab-delimited text file that includes the station's information that is attached to an e-mail alert message. The e-mail alert is intended to send the relevant staff on duty. However, the spatial web-based distribution system is open to all users through the Internet.

\section{RESULTS}

Monthly rainfall and water levels were collected to provide a better understanding of the entire river network and to focus on the risk areas. The automated near-real-time system acquires data continually, manipulates it, and updates the online visualization web service. A warning message containing the information will be sent. The results for each operation are presented below. 
A. Water Levels and Rainfall Patterns along the River

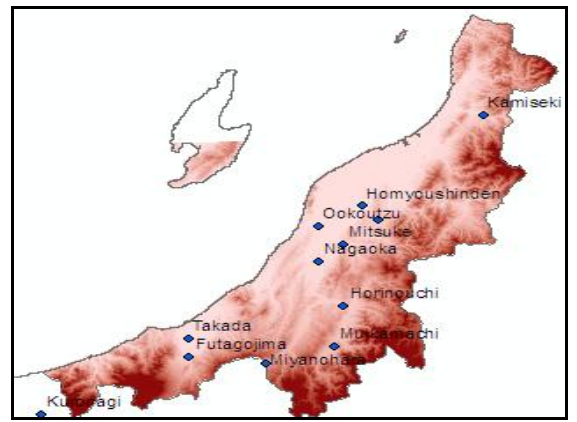

Fig. 8. Water-level stations in Niigata.
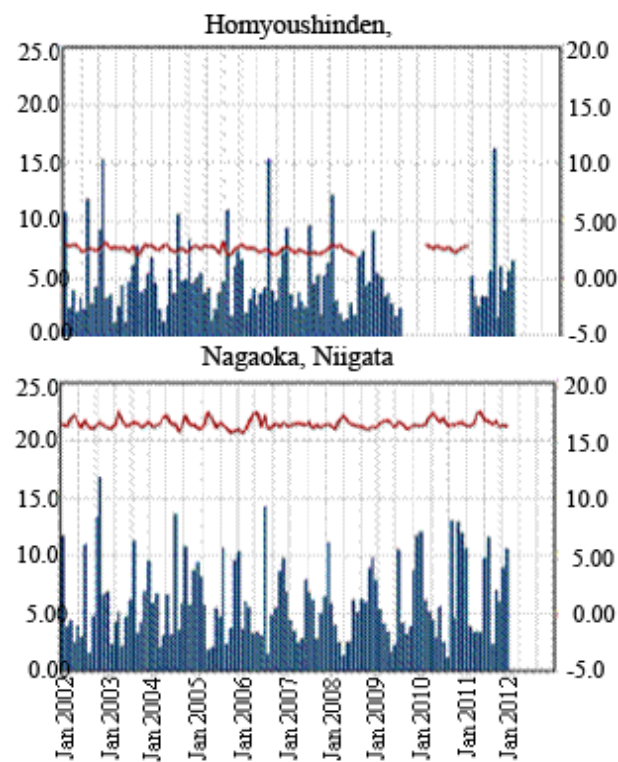

Fig. 9. Water level and rainfall, Niigata.

Rainfall (mm)

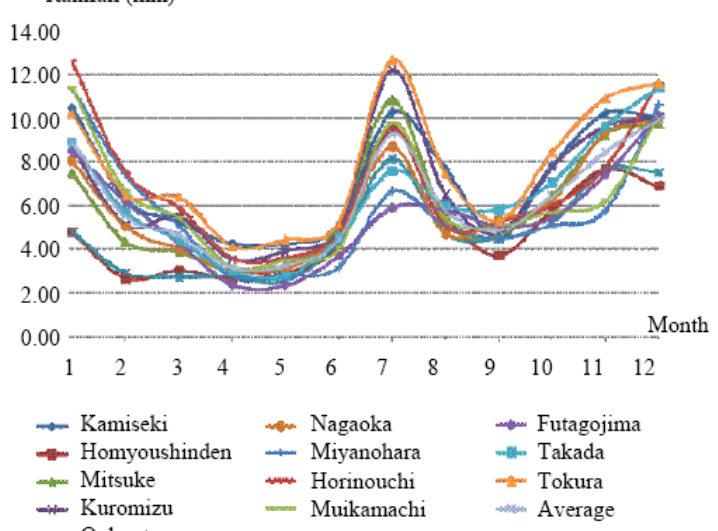

* Ookoutzu

Fig. 10. Rainfall in Niigata.

Monthly data from 2002 to 2012 were plotted for each pair of stations where they appeared at the same location. Fig. 8 and Fig. 9 show the rainfall-water-level data for Niigata. The river basin flows downward and from east to west. The study found that the sources of water in these areas included the dam and the neighboring river lines. In general, the most rainfall occurs in July. The upper part of the region had higher rainfall intensity than the lower part (Fig. 10). Most of the observed prefectures had high rainfall in March, July and September, except for Niigata. Rainfall intensity in Niigata was higher in January and July and lower in September (Fig. 11).

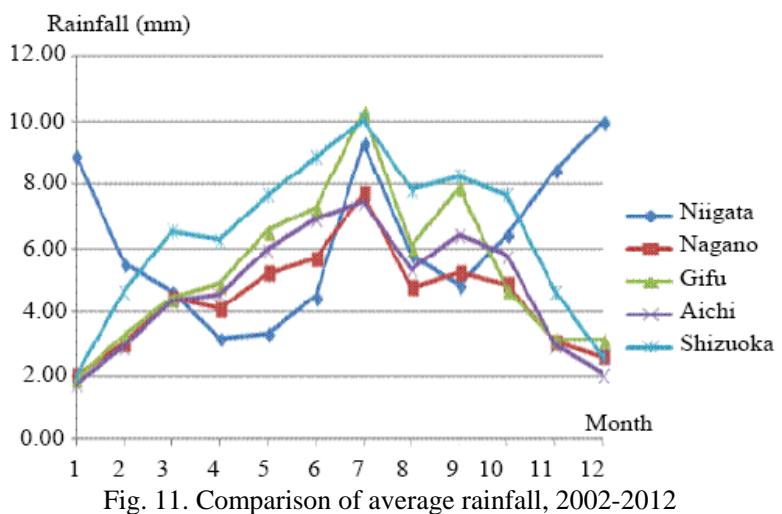

\section{B. Rainfall Data Retrieval and Distribution}

The system is scheduled to acquire data and refresh at ten-minute intervals. The resulting map shows the rainfall intensity with different legend colors (Fig. 12).
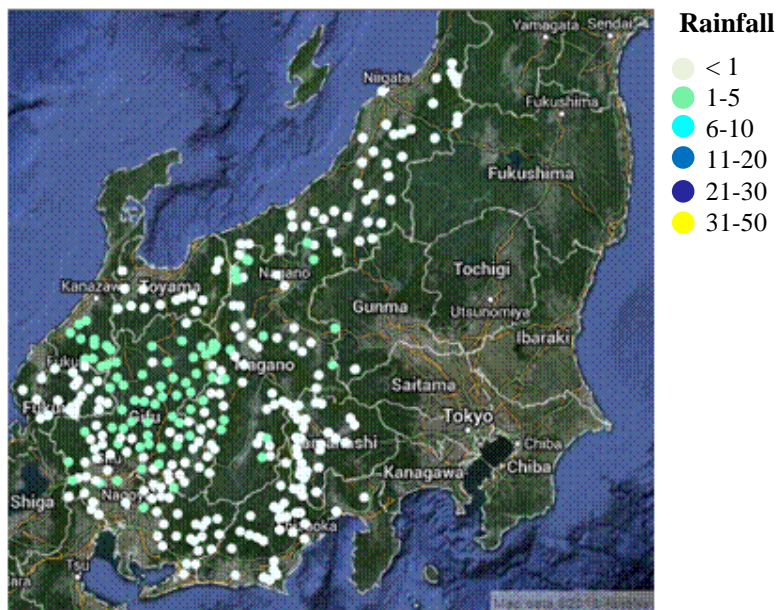

Fig. 12. Rainfall overlay in the map service.

\section{Water Levels and the Degree of Flood Risk}
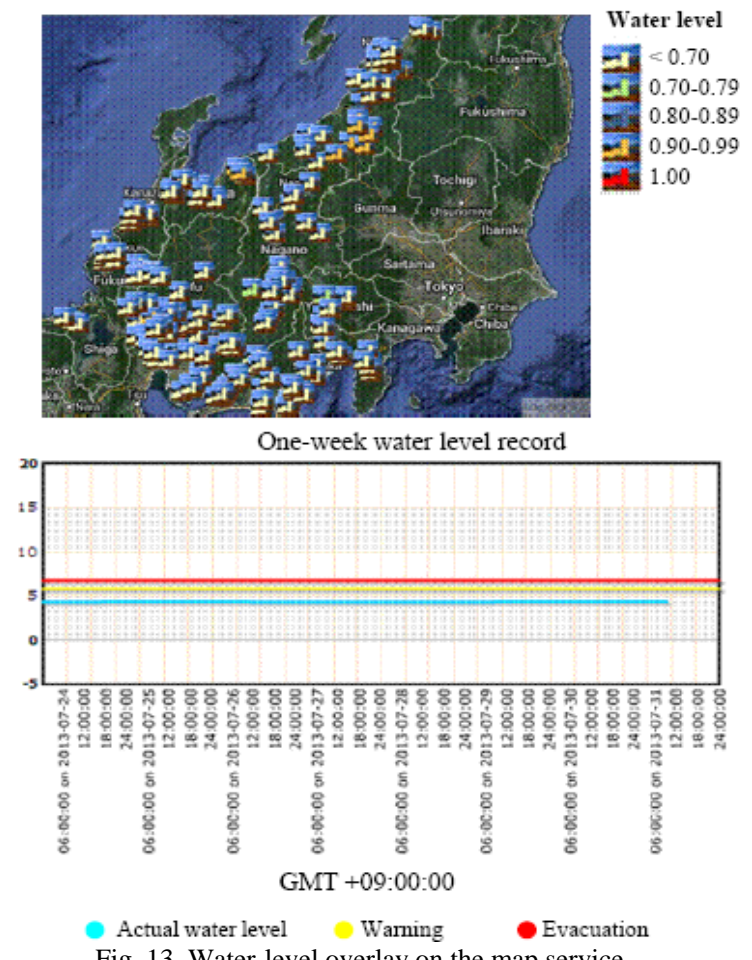

Fig. 13. Water-level overlay on the map service. 
The water-level retrieval time period is similar to the one for rainfall. However, there is group classification based on whether the current water level is reaching the warning level. The calculation is performed as follows (Equation 1):

$$
\text { Current } \text { water level }=\frac{\text { actual value }}{\text { warning value }}
$$

A result value close to 1 means the actual water level is close to the warning level, indicating danger (Fig. 13).

\section{Near-Real- Time Flood-Alert Message}

If the current water level reaches the threshold warning value, the map will display the red warning mark. The alert message will be sent through e-mail. While testing the system, an e-mail message was received from the monitoring system on July 1, 2013. An error was found in the original data source (Fig. 14). Owing to the regular data-receiving period, the next ten-minute refresh was back to normal. While the system helps to save time, human labor is still necessary to make a final decision about whether there will be an announcement.

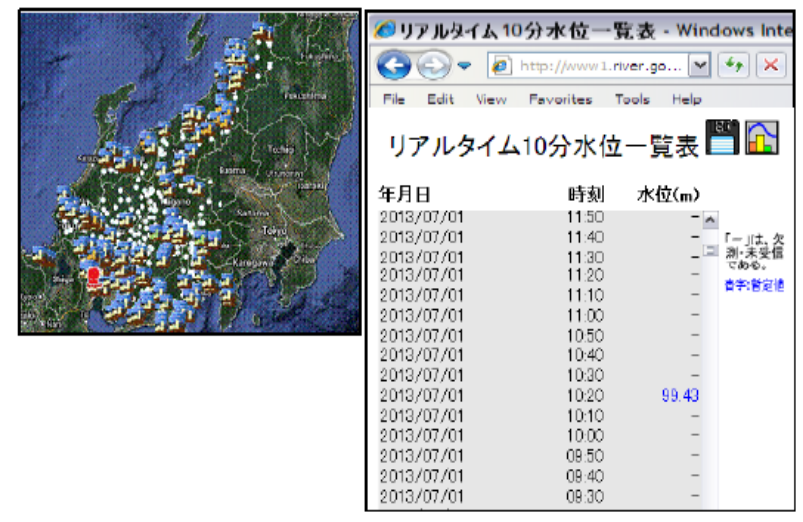

Fig. 14. The warning sign error on July 1, 2013 (10.10 AM)

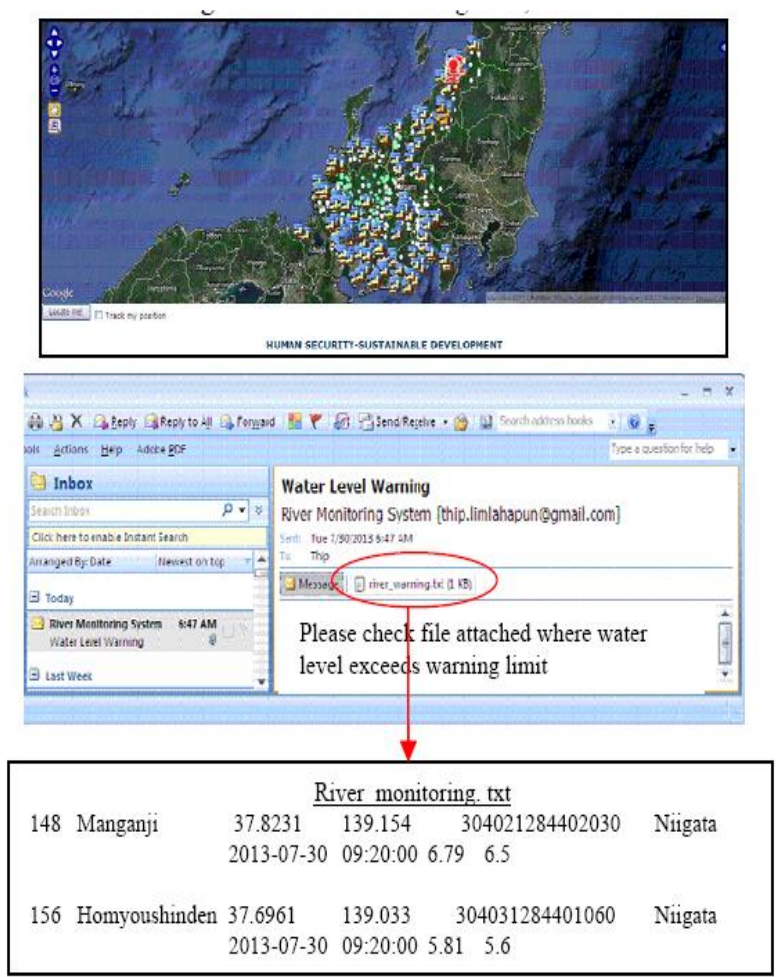

Fig. 15. Flood early-warning on July 30, 2013 (9.20 AM).

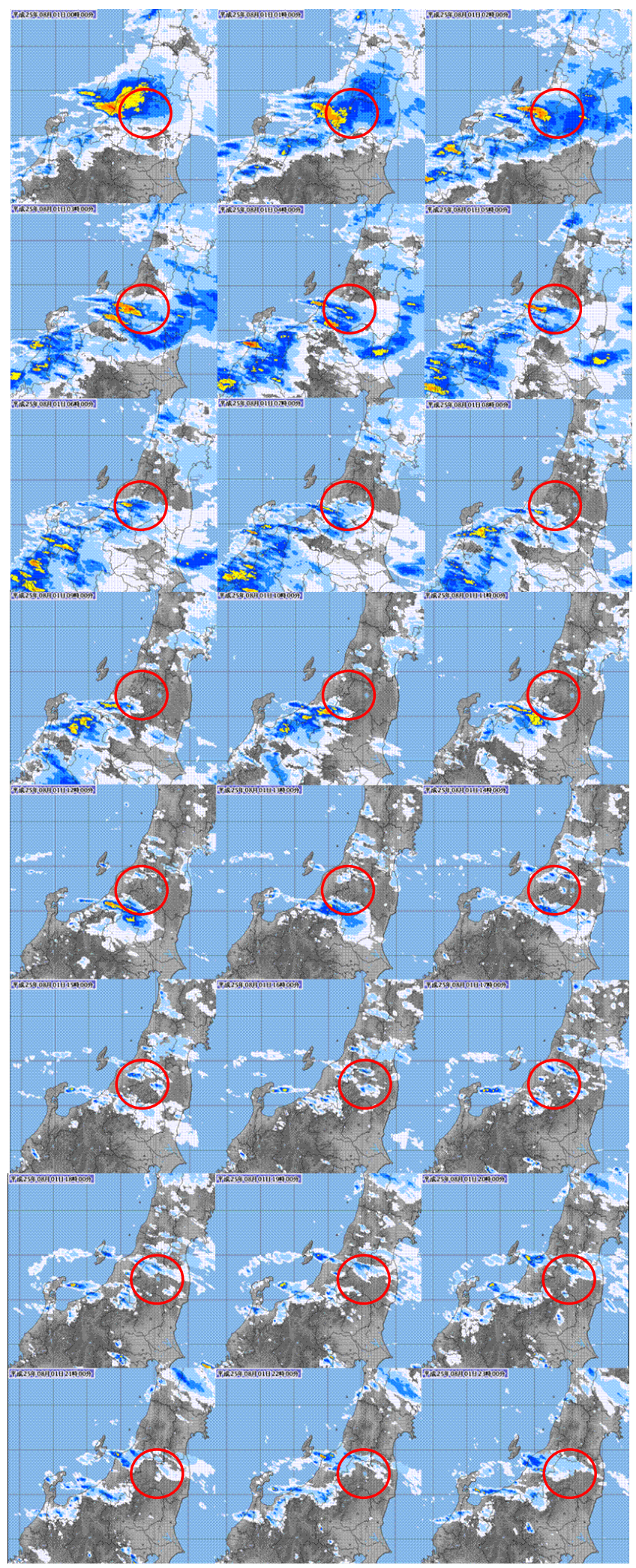

Source: Japan Meteorological Agency [3]

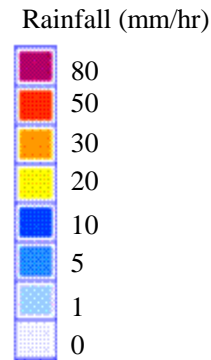

Fig. 16. Rainfall images on August 1, 2013. 
Heavy and continuous rains during July 29-30, 2013 caused the water lifted up in some part for Niigata and the system sent the alert message through e-mail (Fig. 15). Water-level in the river networks is reflected a quantity of rainfall; water-level found decreased within several hours when there was no rains filled (Table I and Table II). Fig. 16 shows the rainfall images observation on August 1, 2013.

TABLE I: WARNING LEVEL ON JULY 30, 2013

\begin{tabular}{|c|c|c|c|}
\hline \multicolumn{4}{|c|}{ Manganji Water-level Station } \\
\hline Warning level (m.) & \multicolumn{3}{|c|}{6.5} \\
\hline Evacuation level (m.) & \multicolumn{3}{|c|}{} \\
\hline & Date & Time & Level (m.) \\
\hline Exceed warning level & $2013-07-30$ & $06: 20$ & 6.53 \\
\hline Back to normal & $2013-07-30$ & $19: 00$ & 6.48 \\
\hline Homyoushinden Water-level Station \\
\hline Warning level (m.) & \multicolumn{3}{|c|}{5.6} \\
\hline Evacuation level (m.) & 7.16 \\
\hline \multicolumn{2}{|c|}{} & Time & Level (m.) \\
\hline Exceed warning level & $2013-07-30$ & $07: 30$ & 5.62 \\
\hline Back to normal & $2013-07-30$ & $13: 40$ & 5.58 \\
\hline
\end{tabular}

TABLE II: WARNING LEVEL ON AUGUST 1, 2013

\begin{tabular}{|c|c|c|c|}
\hline \multicolumn{4}{|c|}{ Homyoushinden } \\
\hline Warning level (m.) & \multicolumn{3}{|c|}{5.6} \\
\hline Evacuation level (m.) & \multicolumn{3}{|c|}{7.16} \\
\hline & Date & Time & Level (m.) \\
\hline Exceed warning level & 2013-08-01 & $05: 20$ & 5.62 \\
\hline Back to normal & 2013-08-01 & $19: 40$ & 5.59 \\
\hline \multicolumn{4}{|c|}{ Aramachi } \\
\hline Warning level (m.) & \multicolumn{3}{|c|}{8.5} \\
\hline Evacuation level (m.) & \multicolumn{3}{|c|}{12.0} \\
\hline & Date & Time & Level (m.) \\
\hline Exceed warning level & 2013-08-01 & $05: 20$ & 8.52 \\
\hline Back to normal & 2013-08-01 & $14: 20$ & 8.45 \\
\hline \multicolumn{4}{|c|}{ Osaki } \\
\hline Warning level (m.) & \multicolumn{3}{|c|}{8.7} \\
\hline Evacuation level (m.) & \multicolumn{3}{|c|}{9.5} \\
\hline & Date & Time & Level (m.) \\
\hline Exceed warning level & 2013-08-01 & $05: 50$ & 8.76 \\
\hline Back to normal & 2013-08-01 & $13: 30$ & 8.68 \\
\hline
\end{tabular}

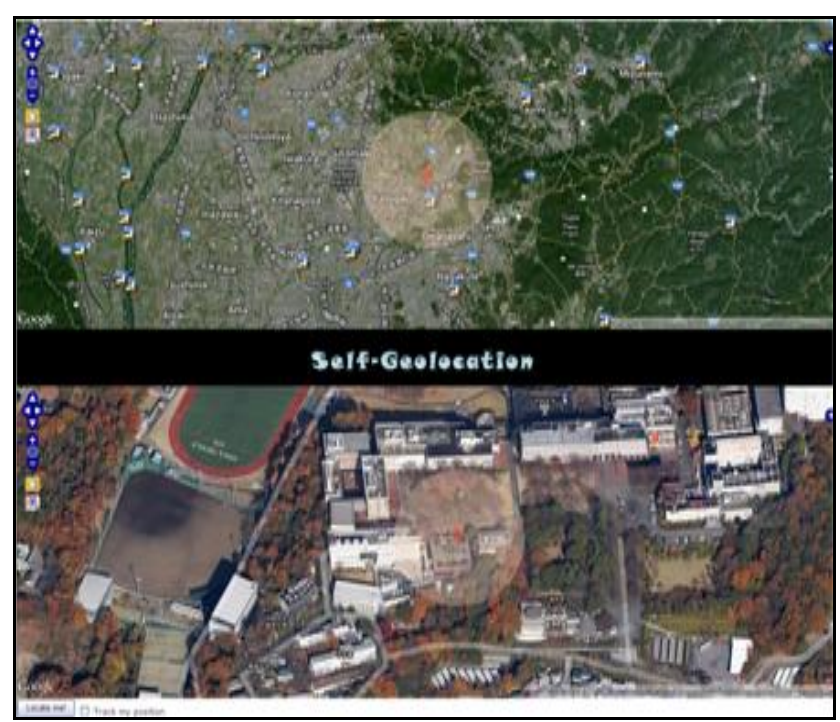

Fig. 17. Self-geolocation.
Self-geolocation is an added web-based function. Users may identify their location, and any risks in surrounding area will be shown (Fig. 17).

\section{CONCLUSION}

Safety planning and disaster recovery are crucial issues for human society. An information-system approach supporting with rainfall images data can rapidly identify flood risks; and can provide early-warning to local community and agencies for necessary flood preparations. It is important to facilitate security for our neighboring communities. Improved on-demand systems can interactively monitor factors that results in flood disaster. The findings have shown that the use of databases and programming environments are well suited for near-real-time warning alerts. It should be noted, however, that the system can readily fail due to data inaccuracy. In-situ equipment could be a limitation of a data receiving failure in severe weather conditions (e.g., storm) or receiving station (e.g. Internet outage).

\section{REFERENCES}

[1] S. D. C. Vimercati, A. Genovese, G. Livraga, V. Piuri, and F. Scotti, "Privacy and security in enviornment systems: issues and solutions," in Computer and Information Security Handbook, 2nd ed. 2013, ch. 47, pp. $835-853$.

[2] K. Vink and K. Takeuchi, "International comparison of measures taken for vulnerable people in disaster risk management laws," International Journal of Disaster Risk Reduction, vol. 4, pp. 63-70, June 2013.

[3] Japan Meteorological Agency, JMA. (July 2, 2013). [Online]. Available: http://www.data.jma.go.jp/obd/stats/etrn/index.php

[4] G. Nigrelli and A. L. L. Marino, "A web-based, open source relational database for rainfall event studies," Computers \& Geosciences, vol. 48, pp. 337-339, November 2012.

[5] M. Careem, C. D. Silva, R. D. Silva, L. Raschid, and S. Weerawarana, "Sahana: Overview of a disaster management system," in Proc. the International Conference on Information and Automation, Colombo, Sri Lanka, December 15-17, 2006

[6] H. Soliman, "The sinking of the Al-Salma Boccaccio 98 ferry in the Red Sea: The integration of disaster support system models and emergency management experience," International Journal of Disaster Risk Reduction, vol. 4, pp. 44-51, June 2013.

[7] S. Belardo and K. R. Karwan, "The development of a disaster management support system through prototyping," Information \& Management, vol. 2, issue 2, pp. 93-102, 1986.

[8] A. Zerger and D. I. Smith, "Impediments to using GIS for real-time disaster decision support," Computers, Environment and Urban Systems, vol. 27, issue 2, pp. 123-141, March 2003.

[9] C. S. Witham, "Volcanic disasters and incidents: A new database," Journal of Volcanology and Geothermal Research, vol. 148, issues 3-4, pp. 191-233, December 2005.

[10] J. L. Pelaez and P. Pigeon, "Co-evolution between structural mitigation measures and urbanization in France and Columbia: A comparative analysis of disaster risk management policies based on disaster databases," Habitat International, vol. 5, issue 4, pp. 573-581, October 2011.

[11] S. J. Ochuodho, "Object-oriented database support for software project management environments: data-modeling issues," Information and Software Technology, vol. 34, issue 5, pp. 283-307, May 1992.

[12] Y. X. Zhou, G. J. Liu, E. J. Fu, and K. F. Zhang, “An object-relational prototype of GIS-based disaster database," Procedia Earth and Planetary Science, vol. 1, issue 1, pp. 1060-1066, September 2009.

[13] S. Li and J. Z. Li, "Scalable and efficient web services composition based on a relational database," Journal of systems and Software, vol. 84, issue 12, pp. 2139-2155, December 2011.

[14] Z. Lin, M. Hamalainen, and A. B. Whinston, "Knowledge-based approach for automating web publishing from databases," Expert Systems with Applications, vol. 4, pp. 1155-1173, 2002.

[15] J. T. Rodriguez, B. Vitoriano, and J. Montero, "A general methodology for data-based rule building and its application to natural disaster 
management", Computers \& Operations Research, vol. 39, issue 4, pp. 863-873, April 2012.

[16] Advanced spaceborne themal emission and reflection radiometer (September 22, 2013). (Aster) Global Digital Elevation Model (GDEM). [Online]. Available: http://gdem.ersdac.jspacesystems.or.jp

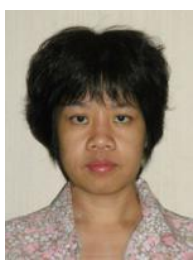

P. Limlahapun obtained her B.S. degree from Thammasat University, Bangkok, Thailand in 1994. She received the master of arts in geography at the Wertern Michigan University in 2002. She received the doctor of philosophy degree in media and governance from Keio University in 2011.

In 2002-2007, she worked at the Geoinformatics Center, Asian Institute of Technology, Thailand as a researcher in the field of an Interactive GIS and Database Management. At present, she is a research fellow of International Digital Earth Applied Science Research Center at Chubu University.

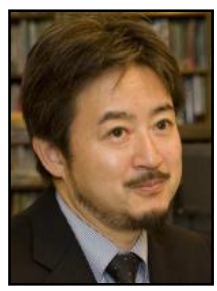

H. Fukui graduated from Nagoya University in 1980 $\mathrm{He}$ received the doctor of science degree in earth sciences from Nagoya University in $1987 . \mathrm{He}$ is professor of Chubu University and serves as the director of International Digital Earth Applied Science Research Center (IDEAS) of Chubu Institute for Advanced Studies in natural disasters from April, 2011. Before joining Chubu University, he was as a professor of the Faculty of Policy Management of Keio University.

His current research interests include regional planning, ecological development, global environment issues and education for sustainable development from the view point of spatial information sciences.

He has served on secretary general of GIS Association Japan, on Board of Directors in International Society for Digital Earth, Center for Environmen Information Sciences, and as an adjunct professor of Chinese Academy of Sciences. 